\title{
ENGINEERING AND CONSTRUCTION PROJECT MANAGEMENT IN THE DIGITAL TWIN ERA \\ Ioannis Patias $^{1}$
}

\begin{abstract}
The aim of this paper is first to describe the current achievements regarding digitalization technologies in the engineering and construction sector. The concrete technologies presented are the GIS standards as CityGLM and BIM technologies, and as the EUBIMTG initiative. These two technologies can be applied in a common framework building digital twin environments and platforms. These platforms create a huge capacity of gains for the constructions sector in all phases, and for all the actors, as constructions digitalization has a huge unexplored potential. Most of the participants in the value chain will gain from interventions in the engineering and construction $(\mathrm{E} \& \mathrm{C})$ phases of design, and engineering, construction and operations. Project management (PM) was described as intervention, which creates potential for new business models to be implemented. Virtual modelling can further develop in the direction of virtualization and construction simulation, and contribute towards the successful digitalization of the E\&C sector.
\end{abstract}

UDC Classification Number: 910.1, DOI: https://doi.org/10.12955/pns.v1.127

Keywords: GIS, BIM, digital twin, E\&C, project management.

\section{Introduction}

For almost 40 years now Geographic Information Systems (GISs) are used as industry standards. GIS are computer-assisted systems that are used for capturing, storage, retrieving, analyzing and displaying spatial data (Clarke, 1986). Since the 1980s they have increase in use and their sophistication has led to new academic interests, which have resulted in an expanding research community in many directions. We have now formalized definitions, categorizations, terminologies and standard data structures, showing a remarkable degree of cross-disciplinary work. Just to mention a few of those standards, CEN TC287 GIS, for the standardization in the field of digital geographic information for Europe, International Standardization Organization (ISO)/TC211 GIS, for the standardization in the field of digital geographic information, and the of course the Open Geospatial Consortium, as an international not for profit organization committed to making quality open standards for the global geospatial community.

But still there are many more opportunities available as a result of the application of new technologies, materials and tools. According to the World Economic Forum (World Economic Forum, 2016) productivity can be improved by using digital technologies. This can also help in the direction of reducing any project delays. Even buildings quality can be enhanced, and working conditions improved. All the above could be achieved in compatibility with the environmental requirements, and Building Information Modeling (BIM) is a central enabling and facilitating point for such technologies.

These increase the interest for the integration of BIM and GIS (Petrova, Ilieva, 2018-1). Although BIM and GIS applications and environments are quite different, both have strengths, and make progress and steps in advancing technologies including twin cities. As a comparison we may refer to the BIM that uses 3D geometry based on Industry Foundation Classes (IFC). The ISO IFC standard is primarily used for representing constructively solid geometry, with boundary representation using Boolean operations. The produced data modeled with IFC are basically used in exchanging information on a project basis between project stakeholders, and partners. Therefore, BIM is used in model buildings and other similar constructions, and structures above the ground, and it is typically used for new buildings, constructions and other structures. Another very important concept regarding BIM models is the decomposition and further specialization of objects in the model. This makes the relation between different objects to be of strong importance.

On the other hand, the GIS systems have a server-focused approach. The focus of GIS data is on the geo-location by using real world coordinates. Geospatial objects in the GIS environment are getting related by using those real world coordinates. The role of the GIS modeler is to model existing data, enhanced with other tools or policies. Until now GIS has been proven to be strong on 2D geometry and now is also getting standardized with 3D geometry.

\footnotetext{
${ }^{1}$ University of Sofia "St. Kliment Ohridski", Faculty of Mathematics and Informatics, Department Computer Informatics, Bulgaria, patias@fmi.uni-sofia.bg
} 
BIM and GIS technologies can create strong synergies when used together in a digital twin environment. The digital twin environment consists of information, which can describe objects in different levels, atomic or macro geometrical. We can then use identically the physical object or the digital twin, and obtain any information (Grieves \& Vickers, 2016).

The aim of this paper is to evaluate the opportunities and describe the business models for the Engineering and Construction (E\&C) sector, which the two technologies GIS, and BIM create in an integrated digital twin environment.

\section{Methodology}

The integration of the two concepts (of GIS and BIM) should use the strengths from both of them, in the context of the other. This can be done by using a central model server for GIS like CityGML (Van Berlo, 2009), with a thematic module for building information modeling based on the EU BIM task force guidelines. This architecture allows us to integrate EU BIM semantics into CityGML. The integration of BIM and GIS generates even more applications from both domains if combined in a digital twin platform. Finally, this new approach can create additional business models for the E\&C sector.

\section{GIS standards and CityGML}

There is an increasing interest in building virtual 3D city models, focused on different application areas. Starting from systems for urban planning, to mobile telecommunication modeling, disaster management systems, and 3D cadaster. Also, systems focused on tourism, for applications in vehicle and pedestrian navigation. The first virtual 3D city models were defined as purely graphical models, and were without any additional semantic aspect. Thus, they could only be used for visualization purposes and there was no possibility for thematic queries. As a result, those systems had also limited reusability of their models in other city models, and thus a more general modeling approach was necessary in order to answer to those information specifications for different applications and fields.

CityGML is the answer to this challenge, as a common semantic information model, enabling the representation of 3D urban objects, and their sharing over different applications. This capability namely is the most important regarding the cost-effective, and sustainable maintenance of a 3D city model. This allows the developers to sell the same platform to many different customers from many different applications and fields. And again, the applications and the fields vary from city planning, and architectural design, to tourist and leisure activities, vehicle and pedestrian navigation, but also environmental simulations, mobile telecommunication, and disaster management, homeland security, and real estate management.

CityGML is an open data model. It is designed in a XML-based format. Based on that, virtual 3D city models can be stored and exchanged. Geography Markup Language 3 (GML3) is used for the implementation. This is an international standard for both exchange and encoding of spatial data. Open Geospatial Consortium (OGC) issued this standard (OGC CityGML, 2012).

The main idea is that CityGML defines the necessary classes and relations. Those classes and relations then can be used in representing cities and regional models as topographic objects. The added value is that any information can be used for their geometry, topology, related appearance properties, and semantical representation. This way the "City" gains a broader definition including built structures, elevation information, vegetation, and water bodies' data, and even "city furniture" components, usually called thematic modules. The model includes generalization hierarchies combining those thematic modules, as relations between objects, and spatial properties. CityGML can be applied both to large areas and small regions and can be used to represent terrains and 3D objects with different levels of detail (LOD) simultaneously, (see fig. 1). LODs are required to reflect independent data collection processes with differing application requirements.

BIM standards and EU BIM task force

The concept of BIM has existed since the 1970s (Eastman et al., 1974). There are many different definitions of BIM by providers varying from Wikipedia to the ISO. Most of them describe BIM as a process or method of managing information related to facilities and projects in order to coordinate multiple inputs and outputs, using shared digital representations of physical and functional characteristics of any built object, including buildings, bridges, roads, and process plants. 


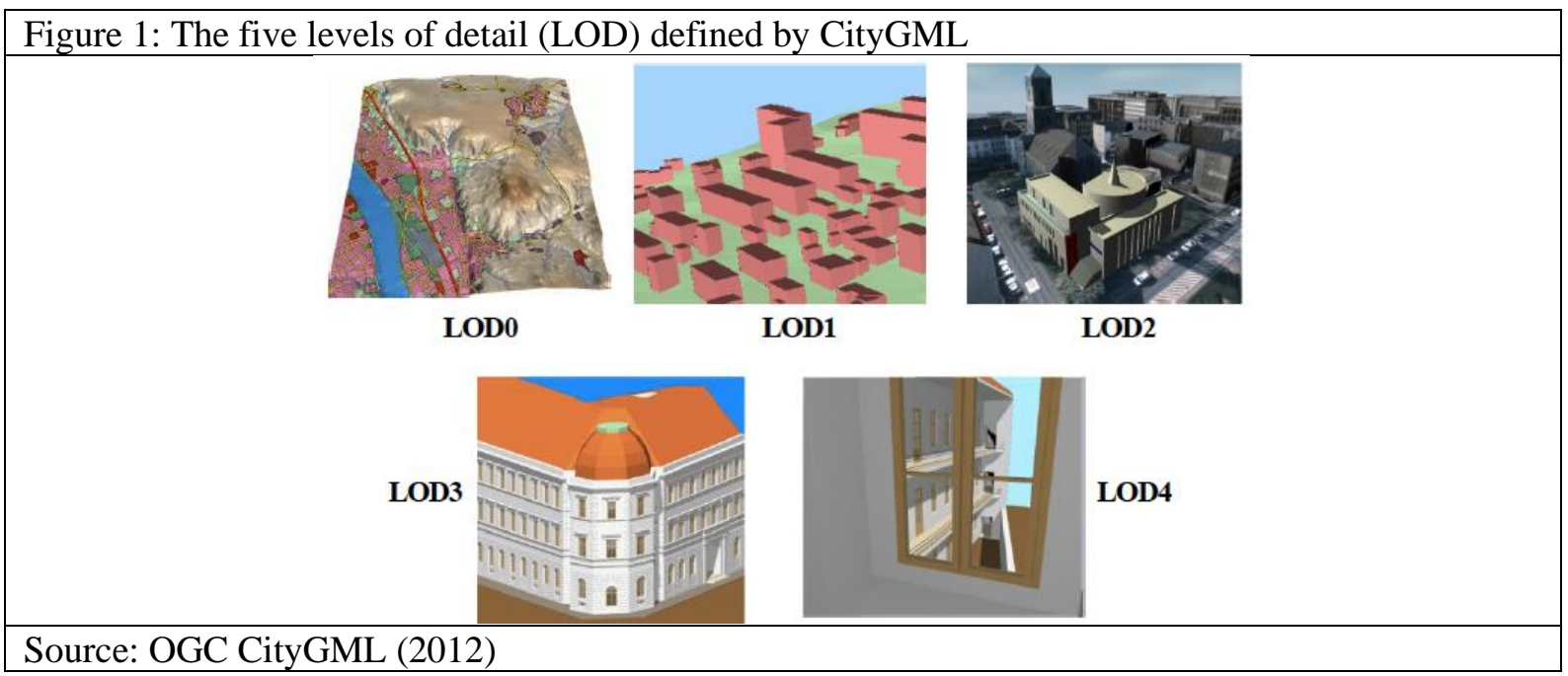

A pan-European approach to best practice in BIM was established; aiming to combine efforts in developing a digital construction sector. This would help in avoiding questions related to common understandings about, how to introduce BIM at a project, organizational or national level (Honic et al., 2019).

In answering the challenge of successful construction sector transformations, in realistic time frames divided into phases, strategic frameworks should be implemented. This is the current experience as gained by EUBIMTG so far (EUBIMTG, 2017).

Further in this direction, Industry Foundation Classes (IFCs) for open BIM data model specifications have being developed and maintained by buildingSMART. This leading organization also contributes International Framework for Dictionaries Libraries, data dictionaries, related-processes and data delivery manuals. This is a significant standardization area for the construction industry and BIM, namely the information exchange area between different software applications (Poljanšek, 2017).

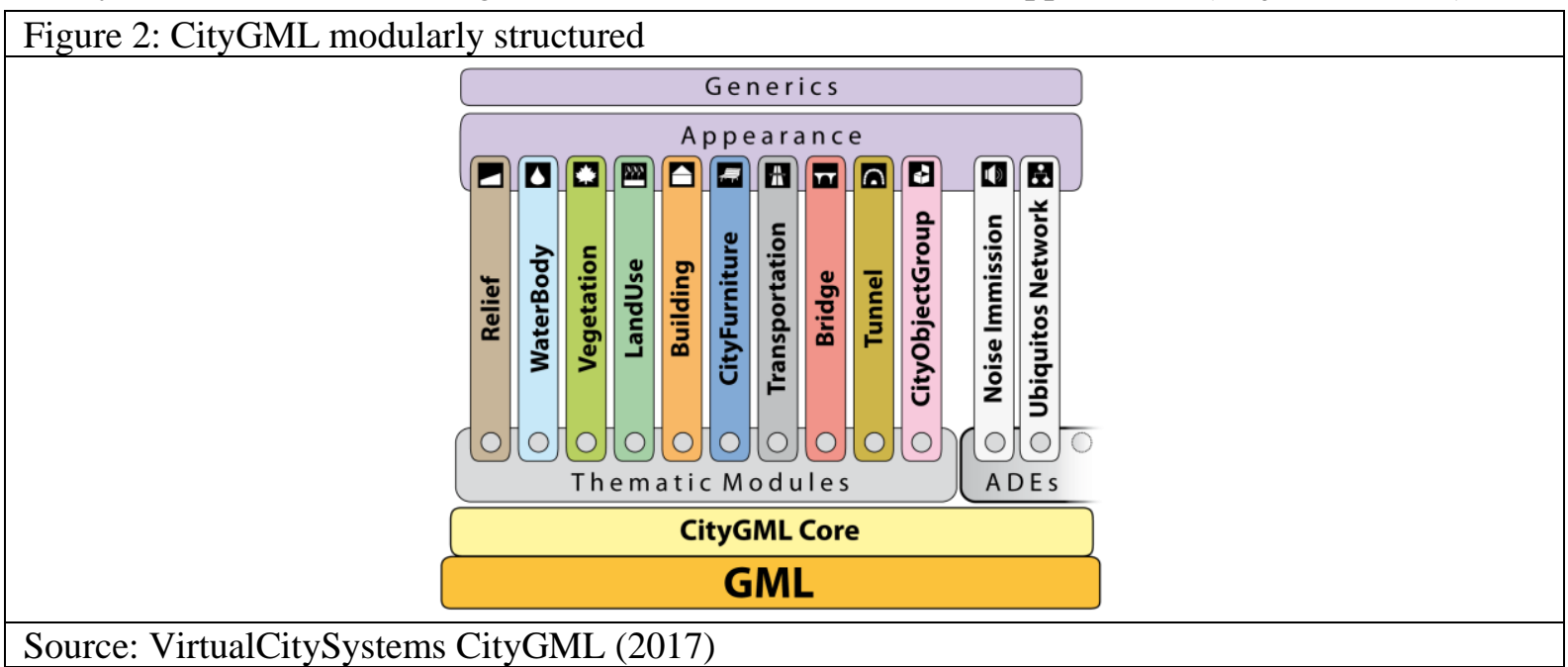

EU BIM as thematic module in CityGML

But the fact that CityGML is modularly structured and covers various thematic areas of a city covering buildings provides us with the opportunity of incorporating EU BIM standards in the CityGML frame. And again, we have the ability to represent each object in the city in the above-mentioned levels of detail (LOD) (see fig. 2). This is because CityGML offers the flexibility of supplementing the data model with domain specific object types and attributes, and therefore guarantees a high degree of interoperability with other systems (Petrova \& Ilieva, 2018-2).

\section{The E\&C value chain}

Looking from a non-technical perspective we may see that E\&C companies, on their own, need to understand their full capacity. We see a fragmented industry, where all participants, based on a project 
life cycle model, and along the whole value chain rely on a seamless interplay. As an answer, common standards, and goals need to be defined, and enhanced coordination with close cooperation along the value chain needs to be implemented (World Economic Forum, 2016). And this is why we need to look closely to the $\mathrm{E} \& \mathrm{C}$ industry value chain (see fig. 3 ).

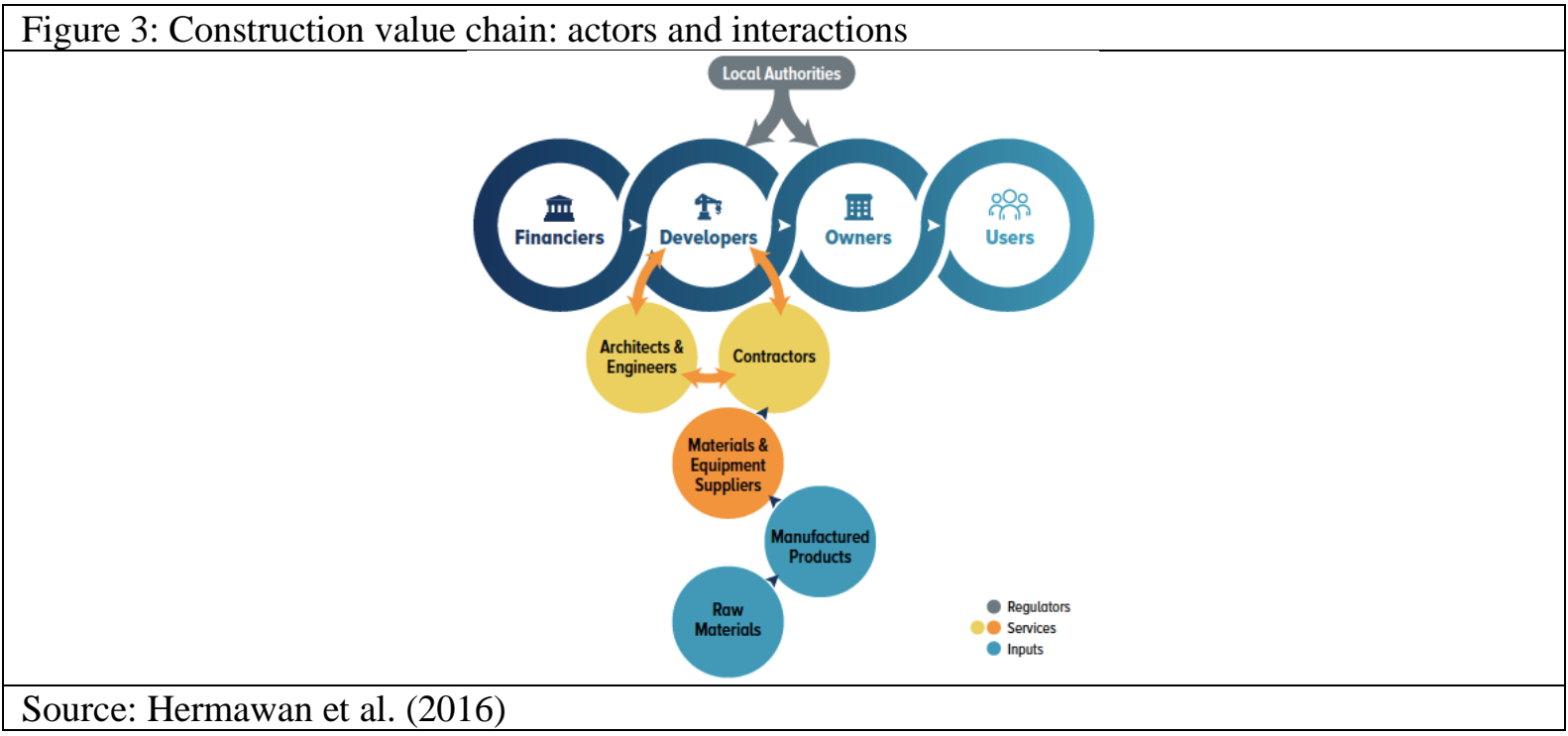

Construction affects apart of all the firms active along the value chain, like building materials and chemicals suppliers, and suppliers of construction equipment. It also affects contractors, engineering, architecture and planning firms together with project owners and developers. Local authorities, and governments have an impact both as regulators but also as main clients, and procurers of the biggest and most of the infrastructure projects.

According to Boston Consulting Group (BCG, 2016) digitalization changes the game fundamentally in $\mathrm{E} \& \mathrm{C}$, not only enabling efficiency and quality gains along the value chain but also reshuffling the competitive league table of companies and countries.

Within ten years, according to BCG estimates, full-scale digitalization in non-residential construction will lead to annual global cost savings of $\$ 0.7$ trillion to $\$ 1.2$ trillion (13\% to $21 \%$ ) in the engineering and construction phases and $\$ 0.3$ trillion to $\$ 0.5$ trillion (10\% to $17 \%$ ) in the operations phase.

EY Global Construction \& Engineering (Buisman, 2018) presents where the industry stands today and also gauges how the majority views the potential impact of technology in the future. Thus, BIM stands at the center of a digital transformation of the construction sector.

\section{E\&C project management}

According to $\mathrm{PMBOK}$ "A project is a temporary endeavor undertaken to create a unique product, service or result" (PMBOK, 2017). Thus, the main difference between operations and projects is that projects are unique as scope, and temporary in timeframe. Unique, means that the final outcome of a project has something distinguishing it from other existing products of the organization. When we talk about operations that means we have repetitive elements, which exist in the final outcome of our activity. On the other hand, temporary, means a project has pre-defined beginning and end dates. Respectively a project will end, either when its objectives are achieved, or when it is terminated. Usually termination is the only approach after we conclude that it is not possible to meet the project objectives, or the initial need of the project does not exist anymore.

Project management (PM) is "the application of knowledge, skills, tools and techniques to project activities in order to meet project requirements" (PMBOK, 2017). A project should go through the following processes: initiation, planning, execution, monitoring and controlling, and closing in order to present an accomplished project management. Having the above in mind PM should be considered as a discipline by itself, but at the same time different industries customize it according to their needs for the concrete area of application.

BIM can be also defined as traditional computer-aided design (CAD) systems successor. As such BIM can serve all stakeholders along the value chain. By using virtual modeling and information, BIM can 
simulate different aspects the $\mathrm{E} \& \mathrm{C}$ life cycle. Those aspects grouped by the three $\mathrm{E} \& \mathrm{C}$ phases, namely design and engineering, construction, and operations, generate opportunities such as:

1. design and engineering phase by:

a. providing enhanced design and engineering processes and facilitating their parallelization

b. virtualizing physical structures

c. developing data driven design, and data analytics environments

d. supporting new environment modeling techniques, like simulation and rapid prototyping

e. enabling iterative design and engineering for generating and evaluating design alternatives

2. construction phase by:

a. providing real-time data sharing for integration and coordination

b. optimizing resource usage through data driven construction planning and execution

c. virtualizing building models with detailed information

d. using robots, and intelligent machines for automated and autonomous construction

e. monitoring, surveillance and construction measuring

3. operations phase by

a. providing enhanced tools for operations and maintenance $(\mathrm{O} \& \mathrm{M})$

b. commissioning and virtual hand over using digital devices and techniques

c. developing smart O\&M techniques by merging and analyzing data from multiple sources

d. applying condition monitoring and predictive maintenance techniques

e. enabling decision support tools for repairs and renovations

The two first phases can be approached on an on-project basis, meaning they cover the respective definition for the project as provided by PMBOK.

All the above practically get supported by buildingSMART standards (Bazjanac, and Crawley, 1997). A wide process and information capabilities spectrum is covered and this represents for the builting industry an integrated environment, which includes:

- Industry Foundation Classes [IFC]: as a data model schema, specific for the concrete industry

- Information Delivery Manual [IDM]: as a business processes and data requirements definition and documenting methodology

- Model View Definitions [MVD]: as specifications for data exchange model

- BIM Collaboration Format [BCF]: as the communication protocols, which are both modelbased, and software-independent, and

- buildingSMART Data Dictionary [bSDD]: as the general definitions of BIM objects with their attributes in a standardized library

The industry stakeholders continuously identify efficiency and value creation opportunities, and this increases the above list, as new technology and process standards are defined.

We have industry needs defined and standards able to support more comprehensive tools in the field of virtual modeling and information.

\section{Conclusion}

This paper explored the opportunities of digitalizing the construction sectors. By encouraging the wider introduction of GIS, through the example of CityGML, and combined it with BIM through the example of EUBIMTG, in digital twin platforms and environments the gains are huge for all the phases and for all the participants of the value chain. Most of the participants in the value chain will gain from interventions in the $\mathrm{E} \& \mathrm{C}$ phases of design, engineering, construction and operations. PM was described as intervention which creates potential for new business models to be implemented. Virtual modelling can further develop in the direction of virtualization, construction simulation, and contribute towards the successful digitalization of $\mathrm{E} \& \mathrm{C}$ sector.

\section{Acknowledgements}

This paper is prepared with the support of the GATE project "Big Data for Smart Society", funded from the European Union's Horizon 2020 WIDESPREAD-2018-2020 TEAMING Phase 2 programme under Grant Agreement No. 857155, and the scientific project, GloBIG: cloud integration model 
platform with hybrid massive parallelism and its application for analysis and automated semantic enrichment of large collections of heterogeneous data, contract number: DH 02/9-17.12.2016.

\section{References}

Ad Buisman (2018), EY Global Construction Leader Partner, Real Estate, Hospitality \& Construction, Ernst \& Young Accountants LLP How are engineering and construction companies adapting digital to their businesses?, Retrieved from https://www.ey.com/Publication/vwLUAssets/EY-Digital-survey/\$File/EY-Digital-survey.pdf

Bazjanac, V. and Crawley, D.B. (1997) The implementation of Industry Foundation Classes in simulation tools for the building industry - http://www.inive.org/members_area/medias/pdf/Inive/IBPSA/UFSC585.pdf

Boston Consulting Group (BCG) (2016), Digital in Engineering and Construction - Future of Construction. Retrieved from http://futureofconstruction.org/content/uploads/2016/09/BCG-Digital-in-Engineering-and-Construction-Mar-2016.pdf

Clarke, Keith. (1986). Advances in Geographic Information Systems. Computers, Environment and Urban Systems. 10. 175184. 10.1016/0198-9715(86)90006-2.

Eastman, Charles; Fisher, David; Lafue, Gilles; Lividini, Joseph; Stoker, Douglas; Yessios, Christos (September 1974). An Outline of the Building Description System. Institute of Physical Planning, Carnegie-Mellon University. Retrieved from https://files.eric.ed.gov/fulltext/ED113833.pdf

EUBIMTG. (2017) Handbook for the introduction of Building Information Modelling by the European Public Sector, Retrieved from http://www.eubim.eu/handbook-selection/

Grieves, M. and J. Vickers. (2016) Digital Twin: Mitigating Unpredictable, Undesirable Emergent Behavior in Complex Systems, in Trans-Disciplinary Perspectives on System Complexity, F.-J. Kahlen, S. Flumerfelt, and A. Alves, Editors., Springer: Switzerland. p. 85-114

Honic, M., Kovacic, I., \& Rechberger, H. (2019). BIM-Based Material Passport (MP) as an Optimization Tool for Increasing the Recyclability of Buildings. InApplied Mechanics and Materials(Vol. 887, pp. 327-334). Trans Tech Publications.

Martin Poljanšek (2017), Building Information Modelling (BIM) standardization. JRC Science Hub https://ec.europa.eu/jrc, Hermawan et al., (2016) Draws actors from the graphic, Institut Teknologi Bandung, Indonesia. Retrieved from https://ec.europa.eu/jrc/en/publication/building-information-modelling-bim-standardization

ISBN 978-92-79-77206-1. Retrieved from https://ec.europa.eu/jrc/en/publication/building-information-modelling-bimstandardization

OGC City Geography Markup Language (CityGML) (2012), En-coding Standard, External identifier of this OGC® document: http://www.opengis.net/spec/citygml/2.0, Reference number of this OGC® project document: OGC 12-019. Retrieved from https://portal.opengeospatial.org/files/?artifact_id $=47842$

Petrova-Antonova D., S. Ilieva, D. (2018-1). Future City: A pilot project of GATE Center of Excellence. Serdica Journal of Computing, vol. 12, no. 1, 2018, ISSN 1314-7897.

Petrova-Antonova D., S. Ilieva, D. (2018-2). Smart Cities Evaluation - A Survey of Performance and Sustainability Indicators. 44th EUROMICRO Conference on Software Engineering and Advanced Applications (SEAA), Prague, Czech Republic, August 29th - August 31st, 2018.

PMBOK ${ }^{\circledR}$ Guide, A Guide to the Project Management Body of Knowledge (2017) - Sixth Edition, www.pmi.prg Van Berlo, L. (2009): CityGML extension for Building Information Modelling (BIM) and IFC. Free and Open Source Software for Geospatial (FOSS4G), Sydney.

VirtualCitySystems CityGML (2017), CityGLM Modularly structured based on OGC and Open Geodata Interoperability Specification (OGIS). retrieved from https://www.virtualcitysystems.de/en/solutions\#citygml

World Economic Forum. (2016), Shaping the Future of Construction: A Breakthrough in Mindset and Technology. Retrieved from http://www3.weforum.org/docs/WEF_Shaping_the_Future_of_Construction_full_report_.pdf 